\title{
ANALISIS STABILITAS TANAH TIMBUNAN DENGAN PERKUATAN TURAP KAYU GALAM DI DAERAH RAWA KALIMANTAN SELATAN
}

\author{
Akhmad Gazali ${ }^{1)}$, Fathurrahman ${ }^{2)}$ \\ Universitas Islam Kalimantan MAB Banjarmasin \\ Email: ${ }^{1)}$ akhmadgazali51@gmail.com
}

\begin{abstract}
ABSTRAK
Kalimantan Selatan adalah salah satu daerah yang banyak memiliki lahan rawa. Penggunaan kayu galam ialah salah satu alternatif untuk konstruksi penahan kelongsoran pada tepi jalan di daerah rawa. Kelongsoran sering terjadi pada tepi timbunan jalan di daerah rawa. Tidak jarang terjadi kerusakan akibat kelongsoran pada beberapa ruas jalan. Penelitian ini bertujuan untuk mengetahui pengaruh perkuatan turap kayu galam terhadap peningkatan daya dukung tanah dan stabilitas tanah timbunan akibat bekerjanya gaya luar. Faktor keamanan lereng timbunan secara manual dengan metode irisan fellenius didapatkan hasil SF = $0,857<1,0$ "tidak aman" sehingga akan terjadi keruntuhan pada lereng timbunan. Maka dilakukan analisis stabilitas timbunan secara bertahap, hingga diperoleh kenaikan dari $\mathrm{cu}=1,04 \mathrm{t} / \mathrm{m}^{2}$ menjadi $\mathrm{cu}=1,8 \mathrm{t} / \mathrm{m}^{2}$. Hasil analisis yang dilakukan secara manual diketahui total penurunannya adalah $=284,62 \mathrm{~cm} \approx 285 \mathrm{~cm}$. Untuk hasil simulasi dengan program PLAXIS menunjukan bahwa terjadi penurunan sebesar $3,1 \mathrm{~cm}$.
\end{abstract}

\section{Kata Kunci: lahan rawa, kayu galam, perkuatan turap}

\begin{abstract}
South Kalimantan is one of the areas that has a lot of swamps. The use of galam wood is an alternative to the construction of landslide resistors on the roadside in swamp areas. Landslides often occur on the edge of road piles in swamp areas. Not infrequently damage due to landslides on several roads. This study aims to determine the effect of galam wood plaster reinforcement on increasing soil carrying capacity and stability of embankment due to the operation of external forces. The factor of manual embankment slope safety with the fellenius slice method shows that $S F=0.857<1.0$ "is not safe" so there will be a collapse on the slope of the embankment. Then the embankment stability analysis is carried out gradually, so that an increase from $\mathrm{cu}=$ $1.04 \mathrm{t} / \mathrm{m}^{2}$ to $\mathrm{cu}=1.8 \mathrm{t} / \mathrm{m}^{2}$. The results of the analysis carried out manually revealed that the total decrease was $=284.62 \mathrm{~cm} \approx 285 \mathrm{~cm}$. For the simulation results with the PLAXIS program, it shows that there is a decrease of $3.1 \mathrm{~cm}$.
\end{abstract}

Keywords: swamp land, galam wood, sheet pile reinforced 


\section{PENDAHULUAN}

\section{Latar Belakang}

Kalimantan Selatan adalah salah satu daerah yang banyak memiliki lahan rawa. Tanah rawa termasuk tanah lunak atau tanah berbutir halus. Tanah lunak mempunyai kekuatan geser rendah, kemampatan tinggi dan kapasitas daya dukung yang rendah. Kelongsoran sering terjadi pada tepi timbunan jalan di daerah rawa. Tidak jarang terjadi kerusakan akibat kelongsoran pada beberapa ruas jalan. Kelongsoran yang terjadi oleh beberapa faktor yaitu terlalu tingginya timbunan jalan, stabilitas dari tanah timbunan maupun tanah dasar, pengaruh beban yang terjadi di atas tanah maupun parameter tanah yang menentukan bagaimana sifat dari tanah.

Penggunaan kayu galam ialah salah satu alternatif untuk konstruksi penahan kelongsoran pada tepi jalan di daerah rawa. Kayu galam tersebut akan dimanfaatkan sebagai bahan pembuatan turap untuk menahan kelongsoran yang terjadi pada tepi jalan di daerah rawa. Perlu diperhatikan sifat serta untung ruginya pemakaian kayu galam dalam mengatasi kelongsoran tersebut. Kayu galam dipilih karena dinilai lebih ekonomis, mudah didapat di daerah Kalimantan Selatan yang banyak memiliki rawa serta mudah dalam pengerjaannya. Kerugian kayu galam sendiri adalah harus terendam agar tahan lama serta umur yang lebih kecil dibanding bahan lain. Perlu analisa yang lebih akurat untuk mengetahui apakah kayu galam dapat menjadi bahan turap untuk menahan kelongsoran yang akan terjadi.

\section{Rumusan Masalah}

Berdasarkan latar belakang, berikut ini dikemukakan rumusan masalah sebagai berikut:

1. Bagaimana pengaruh perkuatan turap kayu galam terhadap peningkatan daya dukung tanah?

2. Bagaimana stabilitas tanah timbunan akibat bekerjanya gaya luar menggunakan program PLAXIS V8.2?

\section{Tujuan Penelitian}

Tujuan penelitian ini adalah sebagai berikut:
1. Untuk mengetahui pengaruh perkuatan turap kayu galam terhadap peningkatan daya dukung tanah.

2. Untuk menganalisis stabilitas tanah timbunan akibat bekerjanya gaya luar menggunakan program PLAXIS V8.2.

\section{KAJIAN PUSTAKA}

Perkuatan tanah (reinforcement of earth) didefinisikan sebagai suatu inklusi (penggabungan) elemen-elemen penahan kedalam massa tanah yang bertujuan untuk menaikkan perilaku mekanis. (Irsyam, 1994).

Manfaat perkuatan tanah ini pada site dimana kondisi tanah pondasinya jelek dan areanya marginal, sehingga apabila digunakan teknik perbaikkan tanah yang lainnya umumnya akan lebih mahal.

\section{Daya Dukung Tiang Kayu Galam}

Tiang galam selalu digunakan berdasarkan prinsip friction piles karena panjangnya yang terbatas. Selama ini, daya dukung tiang galam diperhitungkan hanya berdasarkan teoritis atau berdasarkan data hasil uji sondir.

Pada tanah rawa, apabila suatu tiang dipancang masuk ke dalam tanah, maka tanah di sekeliling tiang akan rusak/terganggu sehingga tanah berkurang kekuatannya (sensitivity) yang mengakibatkan daya dukung ultimit tiang lekatan mengecil. Namun seusai fungsi waktu akan terjadi proses pulihnya kembali kekuatan tanah tersebut (thixotropy) hingga pada waktu tertentu kekuatan tanah akan pulih kembali $100 \%$, yang berarti daya lekatan tanah pada tiang akan maksimal sehingga daya dukung ultimit tiang juga akan maksimal.

\section{Penggunaan Konstruksi Cerucuk Untuk Meningkatkan Daya Dukung Tanah}

Pengggunaan cerucuk dimaksud untuk menaikan tahanan geser tanah. Bila tanah terhadap geser meningkat, daya dukung tanah juga meningkat. Asumsi yang dipergunakan dalam kontruksi cerucuk dapat dilihat pada Gambar 1. 


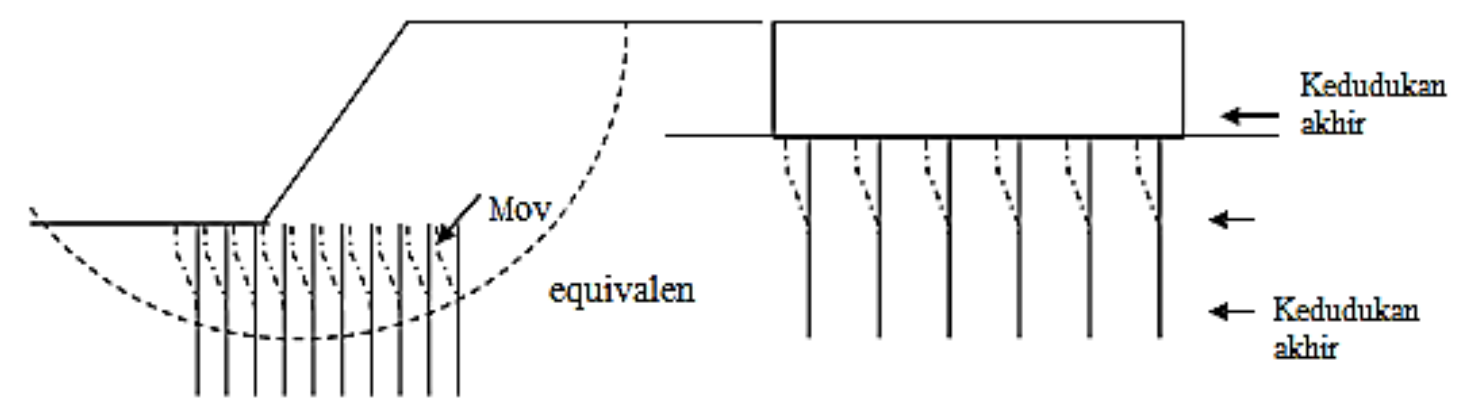

Gambar 1. Asumsi gaya yang diterima cerucuk (NAVFAC DM-7,1971)

Adapun prosedur dari perhitungan kebutuhan cerucuk adalah sebagai berikut (NAVFAC DM7,1971):

a. Menghitung Faktor Kekakuan Relative (T)

$$
\begin{aligned}
& \mathrm{T}=(\mathrm{EI} / \mathrm{f})^{1 / 5} \\
& \text { dimana: } \\
& \mathrm{E} \quad=\text { modulus elastisitas tiang cerucuk } \\
& \left(\mathrm{kg} / \mathrm{cm}^{2}\right) \\
& \mathrm{I}=\text { momen inersia tiang cerucuk } \\
& \left(\mathrm{cm}^{4}\right) \\
& \mathrm{f}=\text { koefisien dari variasi modulus } \\
& \text { tanah }\left(\mathrm{kg} / \mathrm{cm}^{3}\right) \\
& \mathrm{T}=\text { faktor utama kekakuan relatif } \\
& (\mathrm{cm})
\end{aligned}
$$

Elastisitas dasar kayu basah untuk galam:

$\mathrm{E}=97,3 \mathrm{G}+13,1\left(1000 \times \mathrm{kg} / \mathrm{cm}^{2}\right)$

Tegangan lentur kayu basah untuk galam:

$$
\sigma_{\mathrm{lt}}=173,3 \mathrm{G}+124,8\left(1000 \times \mathrm{kg} / \mathrm{cm}^{2}\right)
$$

Berat jenis kayu:

$$
\mathrm{G}=0,4-0,6
$$

b. Menghitung gaya horisontal yang mampu ditahan 1 (satu) tiang

$$
\mathrm{Mp}=\mathrm{FM}(\mathrm{P} \times \mathrm{T})
$$

$$
\begin{aligned}
& \text { dimana: } \\
& \mathrm{Mp}= \text { momen lentur yang bekerja pada } \\
& \text { cerucuk akibat beban } \mathrm{P}(\mathrm{Kg} . \mathrm{cm}) \\
& \mathrm{FM}= \text { keefisien momen akibat gaya } \\
& \text { lateral } \mathrm{P} \\
& \mathrm{P} \quad= \text { gaya horisontal yang diterima } \\
& \text { cerucuk }(\mathrm{Kg}) \\
& \mathrm{T} \quad \text { faktor utama kekakuan relatif } \\
&(\mathrm{cm})
\end{aligned}
$$

Jadi gaya horizontal yang mampu dipikul oleh 1 (satu) cerucuk adalah:

$$
\mathrm{P}=\mathrm{Mp} /\left(\mathrm{F}_{\mathrm{M}} \cdot \mathrm{T}\right)
$$

c. Menghitung banyaknya tiang cerucuk per-meter

$$
\mathrm{n}=\frac{(\mathrm{SF} \text { diinginkan }-\mathrm{SF} \text { yang ada }) \cdot \mathrm{OM}}{\text { Pmax } 1 \text { cerucuk } \cdot \mathrm{R}}
$$

dimana:

$$
\begin{array}{ll}
\mathrm{SF} & =\text { Safety Factor } \\
\mathrm{OM} & =\text { momen penggerak } \\
\mathrm{R} & =\text { Jari-jari putar bidang gelincir }(\mathrm{m})
\end{array}
$$

\section{Perkuatan Turap Kayu Galam}

Metode perbaikan yang dipakai pada cara ini adalah menggunakan perkuatan tanah dengan cerucuk galam. Metode ini sebagai perkuatan yang termurah dan memungkinkan. Sistem ini lebih sesuai untuk lapisan tanah yang selalu basah atau muka air selalu dipermukaan. Prinsip dasar yang harus dipahami adalah beban timbunan dan lalu lintas diatas tanah dasar adalah harus lebih kecil dari daya dukung tanahnya.

Beban Timbunan

$P=\gamma_{t}(H+0,8)$

dimana:

$\mathrm{P}=$ beban timbunan+beban lalu lintas

$\gamma_{t}=$ berat volume tanah timbunan

$0,8=H_{e k}=$ beban lalu lintas ekivalen

$\mathrm{H}=$ tinggi timbunan

Tinggi Timbunan Kritis

$$
H_{k}=5,14 . \mathrm{cu} / \gamma_{t}
$$

pada kondisi: 


\section{$\mathrm{H}+0,8<H_{c r}$ tidak perlu cerucuk \\ $\mathrm{SF}<1,0 \quad$ cari metode perkuatan/ \\ Perhitungan lainnya \\ $1<\mathrm{SF}<1,5 \quad$ Perhitungan diulang \\ jarak cerucuk diperkecil}

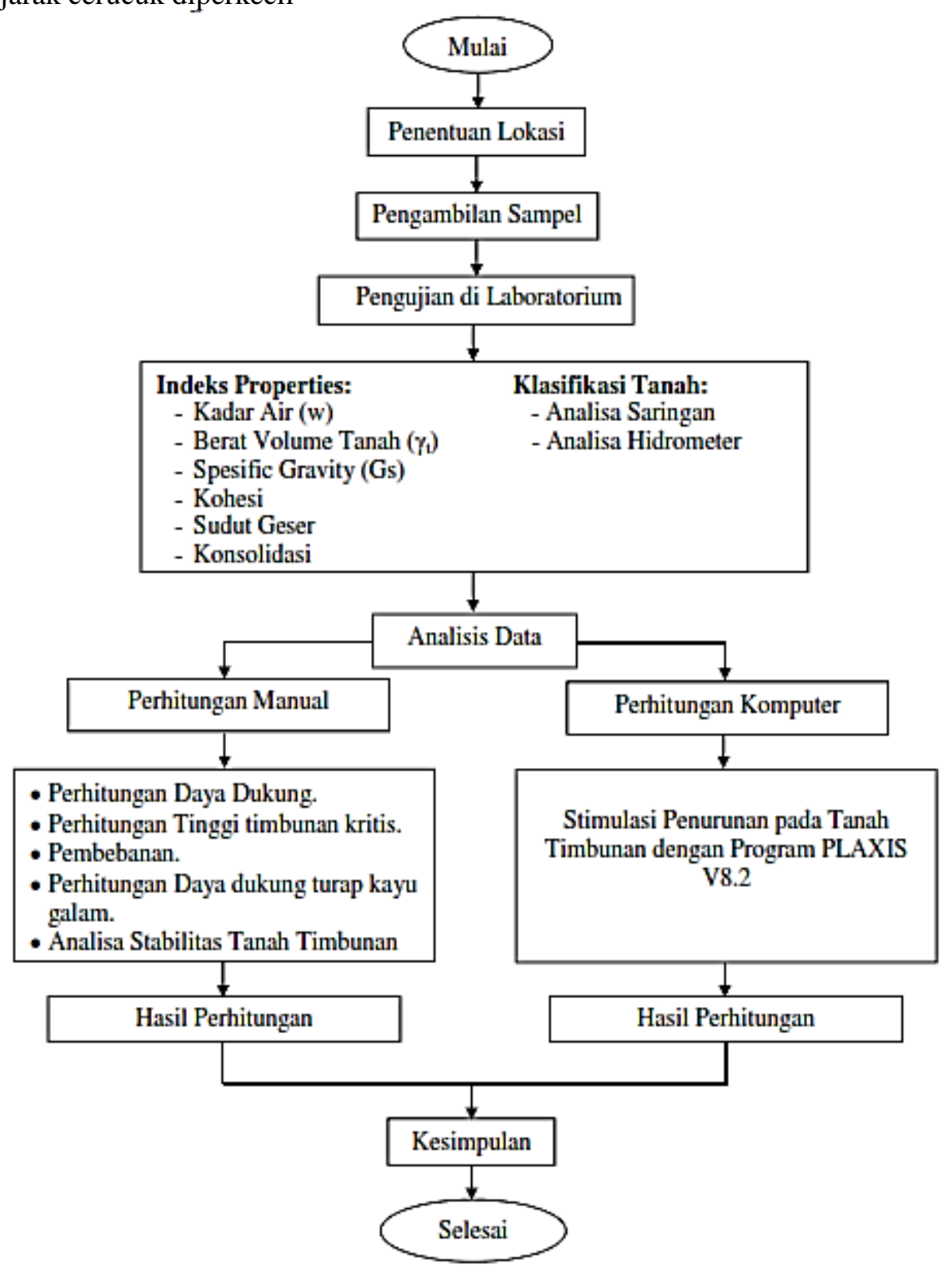

Gambar 2. Bagan Alir Penelitian

\section{METODE PENELITIAN}

Dalam penyusunan penelitian ini metode penulisan yang digunakan berupa tahapan-tahapan dimulai dari tahapan studi literatur, survey lapangan, tahap pengumpulan data, tahap analisis dan tahap mengambil kesimpulan

\section{HASIL DAN PEMBAHASAN}

\section{Parameter Data Tanah}

Data tanah asli ini diambil dari hasil penelitian di Kabupaten Batola yaitu di Desa Simpang Nungki Kecamatan Cerbon, Kalimantan Selatan

Data timbunan berupa tanah lempung berplastisitas sedang, yang diambil di Gunung 
Analisis Stabilitas Tanah Timbunan ..., Akhmad Gazali ${ }^{(1)}$, Fathurrahman ${ }^{(2)}$

Kupang, Kota Banjarbaru Kalimantan Selatan. Data tanah timbunan sebagai berikut:

Kohesi $(\mathrm{c})=0,308 \mathrm{~kg} / \mathrm{cm}^{2}$

Daya Dukung $(\mathrm{qu})=1,792 \mathrm{t} / \mathrm{m}^{2}$
Sudut geser dalam $(\phi)=15^{\circ}$

$\gamma \mathrm{t}=1,86 \mathrm{gr} / \mathrm{cm}^{2}$

$\mathrm{IP}=9,7 \%$

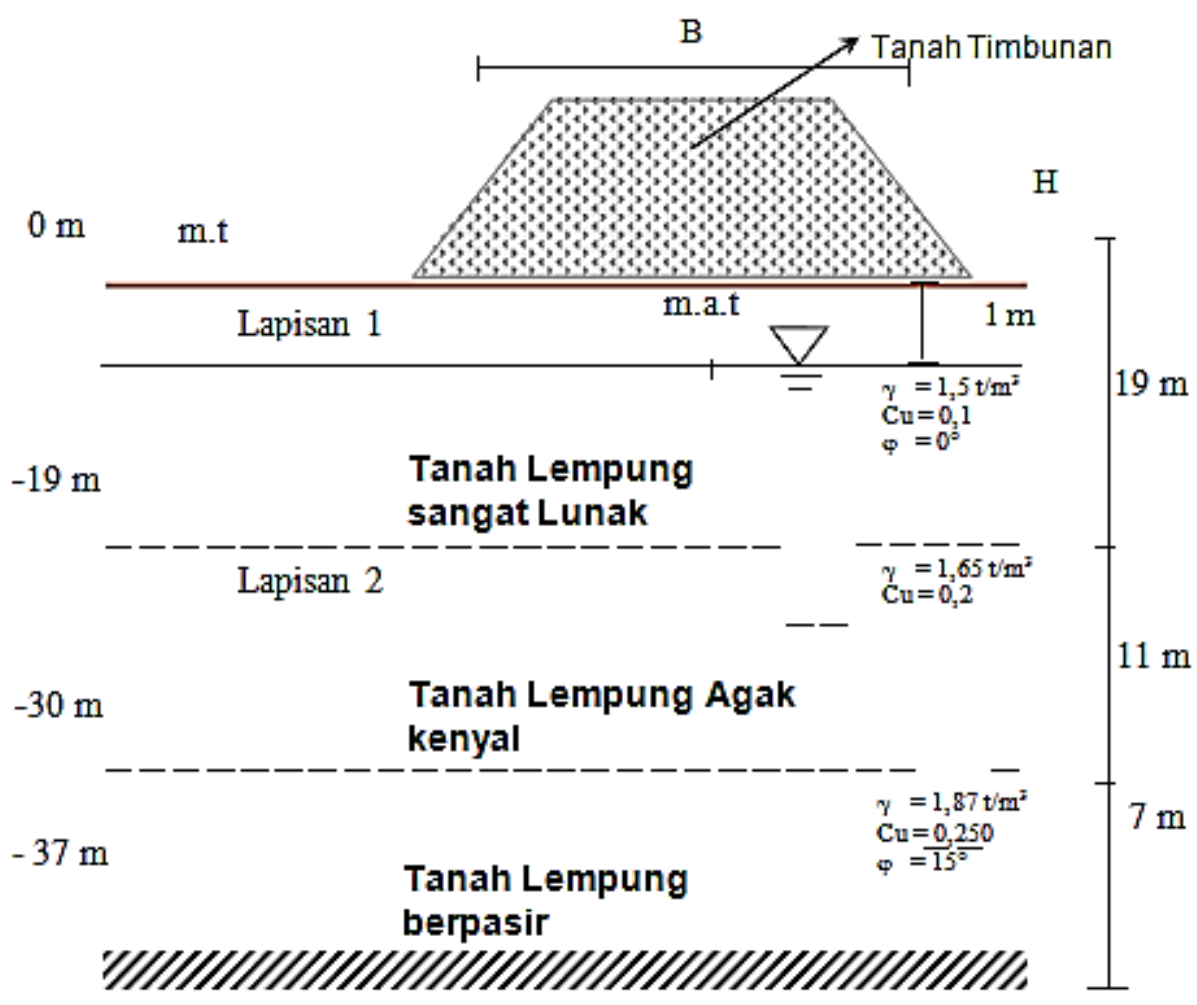

Gambar 3. Lapisan tanah dari rencana timbunan

\section{Rencana Timbunan}

B

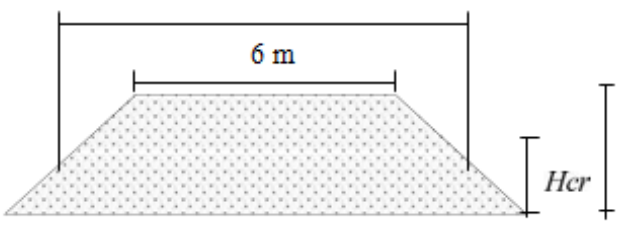

Gambar 4. Rencana Timbunan

Beban dari timbunan:

$$
\begin{aligned}
\mathrm{q}_{\text {timb }} & =(\mathrm{H}+0,8) \gamma_{\text {timb }} \\
& =(3,5+0,8) \cdot 1,86 \\
& =7,998 \mathrm{t} / \mathrm{m}^{2}
\end{aligned}
$$

Faktor keamanan:

$$
\begin{aligned}
\mathrm{FK} & =5928 / 7998 \\
& =0,74 / 1
\end{aligned}
$$

(FK yang diizinkan jika tinggi timbunan $\mathrm{H}_{\text {timb }}=3,5$ m)

Jika diketahui tinggi timbunan rencana $(\mathrm{Hr}=$ $3,5 \mathrm{~m})$ sedangkan tinggi timbunan kritis $(\mathrm{Hcr}=2$ $\mathrm{m})$, maka:
$\mathrm{Hr}=3,5 \mathrm{~m}>\mathrm{Hcr}=2 \mathrm{~m}$ adalah stabilitas timbunan "tidak aman".

Ditinjau dari konsepsi faktor keamanan maka FK $<$ 1,0; timbunan "tidak aman" terhadap penurunan dan kemungkinan terjadi keruntuhan dasar lereng.

Cerucuk galam harus kuat memikul beban sebagai berikut:

Timbunan setinggi $(\mathrm{H})=3,5 \mathrm{~m}$

Beban lalu lintas yang besarnya ekivalen dengan timbunan setinggi Hek $=0,8 \mathrm{~m}$

Beban yang dipikul oleh cerucuk setiap meter persegi dihitung:

$$
\begin{aligned}
\mathrm{Pvu} & =(H+0,8) \cdot \gamma t \\
& =1860 \mathrm{~kg} / \mathrm{m}^{3} \cdot(3,5+0,8) \\
& =7998 \mathrm{Kg} / \mathrm{m}^{2}
\end{aligned}
$$

Daya dukung kelompok cerucuk galam:

$$
\begin{aligned}
\text { Qpg } & =\text { Qs . n } \\
& =22 \cdot 376,99 \\
& =8293,78 \mathrm{Kg}
\end{aligned}
$$


Analisis Stabilitas Tanah Timbunan ..., Akhmad Gazali ${ }^{(1)}$, Fathurrahman ${ }^{(2)}$

Syarat:

Pvu $<$ Qpg

$7998 \mathrm{Kg}<8293,78 \mathrm{Kg} \ldots$.. OK!

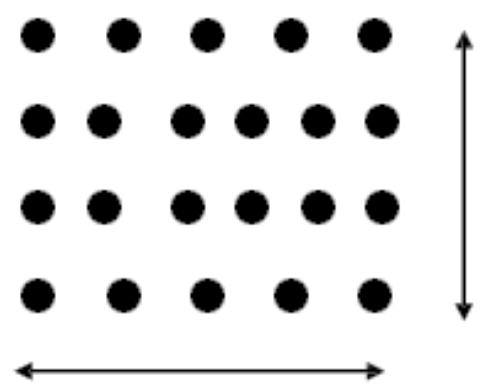

$100 \mathrm{~cm}$

\section{Penurunan Timbunan}

Besar total penurunan timbunan nya adalah:

$\mathrm{S} \quad=\mathrm{Si}+\mathrm{Sc}+\mathrm{Ss}$

$=25,72 \mathrm{~cm}+258,9 \mathrm{~cm}$

$=2,8462 \mathrm{~m}$

$\approx 2,85 \mathrm{~m}$

Gambar 5. Kelompok cerucuk kayu galam per meter persegi

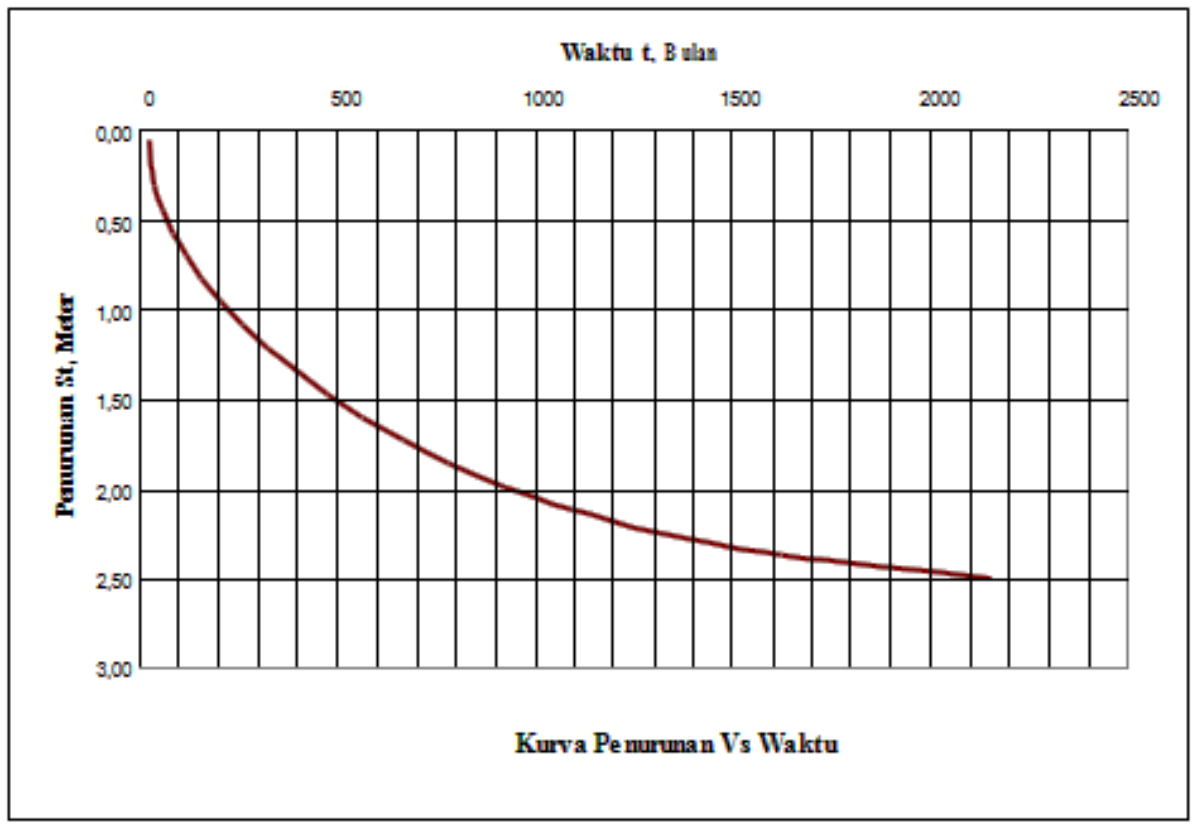

Gambar 6. Kurva Penurunan Vs Waktu

\section{Hasil Analisis Simulasi Pada Timbunan Secara}

Bertahap Dengan Program PLAXIS
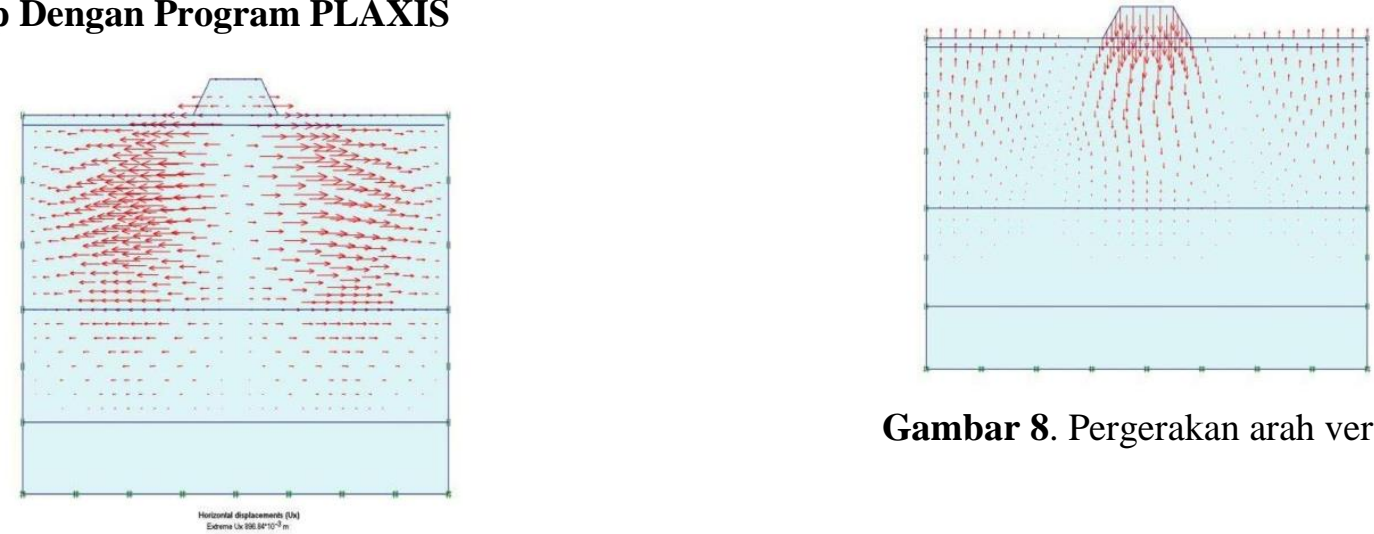

Gambar 8. Pergerakan arah vertikal

Gambar 7. Pergerakan arah horizontal 


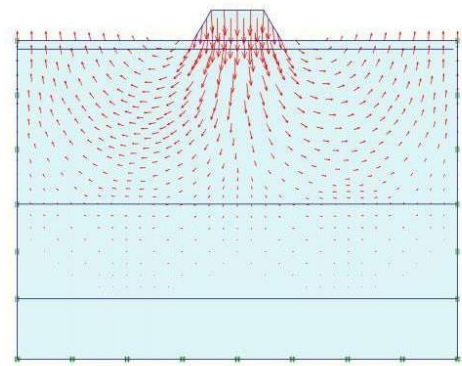

Gambar 9. Pergerakan arah horizontal

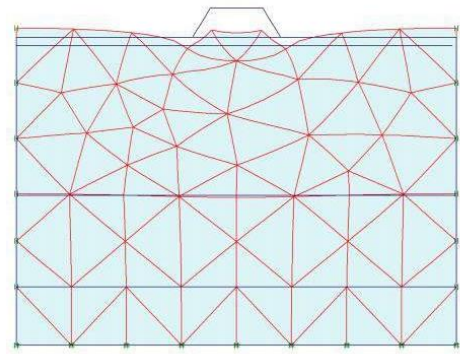

Gambar 10. Simulasi Penurunan yang Terjadi

Dari gambar di atas terlihat bahwa nilai total penurunan besarnya $3,1 \mathrm{~m}$, penurunan yang terbesar terjadi pada tengah timbunan, sedangkan arah pergerakan gaya horisontal, vertikal, dan pergerakan gaya total tanah dapat terlihat pada gambar 7, gambar 8, gambar 9.

\section{PENUTUP}

\section{Kesimpulan}

Untuk menahan berat sendiri timbunan dan beban lalu lintas diperlukan 9 buah cerucuk kayu galam $/ \mathrm{m}^{2}$. Sedangkan untuk menahan kelongsoran lereng tersebut diperlukan cerucuk galam sebanyak $13 \mathrm{buah} / \mathrm{m}$.

Faktor keamanan lereng timbunan secara manual dengan metode irisan fellenius didapatkan hasil $\mathrm{SF}=0,857<1,0$ "tidak aman" sehingga akan terjadi keruntuhan pada lereng timbunan. Sedangkan secara komputasi dengan program bantu XSTABL didapatkan hasil SF $=0,804<1,0$ "tidak aman". Maka dilakukan analisis stabilitas timbunan secara bertahap, hingga diperoleh kenaikan dari $c_{u}=1,04 \mathrm{t} / \mathrm{m}^{2}$ menjadi $c_{u}=1,8$ $\mathrm{t} / \mathrm{m}^{2}$.

Hasil analisis yang dilakukan secara manual diketahui terjadi penurunan pada tanah dasar akibat beban ekivalen timbunan dengan beban lalu lintas. Penurunan yang terjadi adalah total dari penrunan segera dan penurunan konsolidasi primer. Penurunan segera adalah sebesar $21,514 \mathrm{~cm}$ dan penurunan konsolidasi primer selama $=133,0513321$ tahun $=$ 1596,615985 bulan sebesar $258,9 \mathrm{~cm}$. Sehingga total penurunannya adalah $=284,62 \mathrm{~cm} \approx 285 \mathrm{~cm}$.

Untuk hasil simulasi dengan program PLAXIS menunjukan bahwa terjadi penurunan sebesar $3,1 \mathrm{~cm}$.

\section{Saran}

Adanya penelitian lanjutan yang menggunakan sampel penelitian yang lebih banyak khususnya pada tanah rawa.

Untuk mengurangi besarnya penurunan yang berlebihan sebaiknya di beri perkuatan pada tanah dasarnya berupa kombinasi antara timbunan secara bertahap dan perkuatan kayu galam, penimbunan selalu di monitoring penurunannya, apabila dalam jangka waktu 3 bulan penurunannya kurang dari $2 \mathrm{~cm}$, maka penimbunan dianggap selesai. Badan jalan dibangun sampai perkerasan sesuai rencana.

Adanya penelitian lanjutan mengenai pengaruh perkuatan kayu galam terhadap penurunan yang terjadi

\section{DAFTAR PUSTAKA}

Das, B. M., (1998), Mekanika Tanah (Prinsipprinsip Rekayasa Geoteknis), Jilid 2, Erlangga, Jakarta.

Hardiyatmo, H. C., (2002), Mekanika Tanah 2, Gadjah Mada University Press, Edisi-3, Yogyakarta.

NAVFAC DM-7, 1971.

Pusat Litbang Jalan Dinas PU Propinsi Kalimantan Selatan. Mengenal Tanah Lembek dan Problematikanya Dalam Pembangunan Jalan Buku 1. Banjarmasin

Pusat Litbang Jalan Dinas PU Propinsi Kalimantan Selatan. Mengenal Tanah Lembek dan Problematikanya Dalam Pembangunan Jalan Buku 2. Banjarmasin

Robby S., Oktavianti, W., (2008), Analisis Stabilitas Timbunan Secara Bertahap Oprit Jembatan Sarang Halang Kabupaten Paser Tanah Grogot Kalimantan Timur, Skripsi 
Analisis Stabilitas Tanah Timbunan ..., Akhmad Gazali ${ }^{(1)}$, Fathurrahman ${ }^{(2)}$

Universitas Lambung Mangkurat, Fakultas Teknik, Banjarbaru.

Rusdiansyah, (1999), Penggunaan "Stable” Untuk Analisa Stabilitas Lereng, Fakultas Teknik, Universitas Lambung Mangkurat, Banjarbaru.

Saleh, Adinus., Mengenal Tanah Lunak dan Problematikanya Dalam Pembangunan Jalan. RBO. Banjarmasin.

Soedarmo, G. D., (1997), Mekanika Tanah 2, Kamisius, Yogyakarta.

Wesley, L. D., (1977), Mekanika Tanah, Badan Penerbit Pekerjaan Umum, Jakarta. 